\title{
CORPO, EXPRESSÃO E EDUCAÇÃO NA NATUREZA
}

\author{
Terezinha Petrucia da Nóbrega ${ }^{1}$ \\ Bernard Andrieu ${ }^{2}$ \\ Luiz Arthur Nunes da Silva ${ }^{3}$ \\ Lais Saraiva Torres ${ }^{4}$
}

\begin{abstract}
RESUMO: Este ensaio apresenta uma leitura transversal da obra de Georges Hébert e de Émile Jaques-Dalcroze, considerando as relaçóes entre corpo, expressão e educação na natureza. Nesse movimento, a educação faz a passagem da natureza à cultura e da cultura à natureza, ecologizando-se. Assim, o naturismo presente em ambos os estudos funda e atualiza os princípios da ecologia corporal, que envolve o interior de nós, mas também o exterior, em um processo de educação intercorpóreo que envolve o próprio corpo e o corpo do mundo.
\end{abstract}

Palavras-chave: Corpo. Naturismo. Educação física.

\footnotetext{
${ }^{1}$ Universidade Federal do Rio Grande do Norte - Natal (RN), Brasil.

E-mail: pnpbrega68@gmail.com

${ }^{2}$ Universidade Paris Descartes - Paris, França. E-mail: bernard.andrieu@parisdescartes.fr ${ }^{3}$ Universidade Federal do Rio Grande do Norte, Programa de Pós-Graduação em Educação - Natal (RN), Brasil. E-mail: arthur_nunes@hotmail.com

${ }^{4}$ Universidade Federal do Rio Grande do Norte, Programa de Pós-Graduação em Educação Física - Natal (RN), Brasil. E-mail: laissaraiva_@hotmail.com

DOI: $10.1590 /$ CC0101-32622018177914
} 


\section{Body, expression and education in nature}

ABSTRACT: This essay presents a transversal reading of the work of Georges Hébert and Émile Jaques-Dalcroze, considering the relations between body, expression and education in nature. In this movement, education makes the transition from nature to culture and from culture to nature, becoming ecological. Thus, the naturism present in both studies founds and updates the principles of body ecology as a process of education. The ecology of the body involves the interior of us, but also the exterior in an intercorporeal process that involves the body itself and the body of the world.

Keywords: Body. Naturism. Physical education.

\section{INTRODUÇÃO}

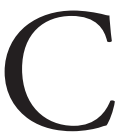

ompreendemos que a experiência corporal é expressiva da nossa existência individual e coletiva. Nesse sentido, a educação, como expressão intersubjetiva, envolve as dimensóes do viver, do ser, do adaptar-se, do relacionar-se, do tornar-se. Trata-se, ainda, da sensibilidade para o autoconhecimento e para o conhecimento, no qual o corpo e os sentidos são fundamentais. Assim, é preciso explorar a qualidade do movimento, sua expressão no espaço e no tempo, como nos ensinaram os pioneiros da dança moderna e da expressão corporal Jaques-Dalcroze, François Delsarte, Isadora Duncan, Rudolf Von Laban, entre outros (WAILLE, 2016). Outra referência significativa dessa compreensão de educação, em particular no que concerne às relaçóes entre o corpo e a educação na natureza, encontra-se na elaboração do Método Natural, de Georges Hébert (SOARES, 2016).

Considerando-se as relaçóes entre a história e a filosofia da educação, destacamos que a educação relacionada ao corpo, à expressão e à natureza já se encontra delineada por Michel de Montaigne (1533-1592) e por Jean-Jacques Rousseau (1712-1778). Em seus Ensaios, Montaigne pensa a educação de crianças associada às regras de civilidade e, portanto, 
a uma educação física, como podemos notar na Apologia de Raymond Sebond, na qual o autor enfatiza a expressão corporal e a inelegibilidade do gesto: "não há gesto ou movimento em nós que não fale, de uma maneira inteligível” (MONTAIGNE, 1972, p. 215). Em 1762, o aparecimento da obra Emílio, ou da Educação, escrita por Jean-Jacques Rousseau, irá colocar a questão da educação conforme as idades da natureza, envolvendo a educação da sensibilidade; a educação do corpo por meio dos exercícios físicos e de preceitos higiênicos. Encontra-se, ainda, em Rousseau (1995) uma educação sensorial, sentimental, moral e estética que ligará o corpo e suas paixóes a uma inelegibilidade cognitiva, afetiva, moral e social.

Ambas as referências vão influenciar diferentes pedagogias corporais, incluindo as obras de Georges Hébert e de Jaques-Dalcroze, sendo ainda atualizadas no campo de uma educaçáo compreendida em um processo de ecologia do corpo. Nossa hipótese é de que a ecologia corporal se apresenta como um princípio e uma prática educativa cuja historicidade encontra-se anexada ao corpo vivo, à experiência vivida, à intercorporeidade e à estesiologia das relaçóes produzidas na passagem da natureza para a cultura e da cultura para a natureza, em uma lógica de descontinuidade e de transformaçóes em ambos os níveis e, notadamente, na história do conhecimento, das ideias e das práticas corporais. Nesse movimento, a educação faz a passagem da natureza à cultura e vice-versa em um processo de ecologização por meio da intercorporeidade - ou seja, da anexaçáo do corpo do outro e do corpo do mundo pelo nosso corpo próprio, conforme Merleau-Ponty nos mostra em sua arqueologia do corpo humano nos cursos ministrados sobre a natureza no Collège de France entre os anos de 1956 e 1960 (ANDRIEU, 2016).

No contexto histórico da educação física na Europa do século XIX, acontecimentos como as revoluçóes burguesas, industriais, científicas e pedagógicas impulsionaram e exigiram um novo modo de compreender e de se relacionar com o corpo, com a natureza, com o movimento humano. A ascensão da burguesia, o desenvolvimento das cidades, o crescimento industrial, as guerras, o conhecimento anatômico, fisiológico, da higiene e da mecânica, a arte do canto, da música e da fotografia, e a preocupação de uma educação moral e física, foram fatos decisivos para as mudanças relacionadas às práticas corporais e à disciplina. As práticas emergentes desse contexto voltavam-se para o corpo em 
movimento entendendo-o a partir dos grupamentos musculares e de seu funcionamento orgânico, fazendo prevalecer uma educação do corpo e do movimento para a utilidade gestual fabril. Influenciadas também pelo Movimento Ginástico Europeu, que resultou nos métodos ginásticos e no esporte moderno, prevaleciam nas práticas o pensamento científico do positivismo bem como a influência da técnica e da ordem médicomilitar (SOARES, 1998).

De acordo com Revel (2015), abordamos a perspectiva histórica das obras de Georges Hébert e Jaques-Dalcroze de forma transversal, enfatizando as relaçóes entre corpo, expressão e educação na natureza. A partir dessa compreensão, fazemos uma leitura do Método Natural de Georges Hébert, considerando os arquivos Hébert do L'Institut Supérieur du Sport et de l'Education Physique, em Paris, e a revista L'Éducation Physique, coordenados por Philippe-Meden (PHILIPPE-MEDEN, 2014; 2017). Os trabalhos sobre Georges Hébert estão ligados à educação pelo Método Natural, mas também à história do naturismo (BAUBEROT, 2004; VILLARET, 2005; ANDRIEU, 2011; PHILIPPE-MEDEN, 2014; 2017; SOARES, 2016). Buscamos, ainda, a referência aos estudos de Jaques-Dalcroze como princípio expressivo para uma educação do corpo, com base na consulta às ediçóes originais disponíveis na Biblioteca Nacional da França (BNF), de 1906; bem como ao texto Souvenirs, Notes e Critiques, escrito pelo autor em 1942.

\section{O MÉTODO NATURAL DE GEORGES HÉBERT}

O naturismo será considerado por Georges Hébert em 1910 e apoiará a elaboração do Método Natural cujos princípios diretores baseiam-se "nas leis da natureza". Nesse método, o princípio de trabalho cotidiano consiste precisamente em "reestabelecer durante um tempo determinado, as condiçóes mesmas da vida natural" (HÉBERT, 1910, p. 17-18). Nessa proposta de educaçáo física, o valor e o sentido conferidos a noçóes como saúde e força evoluem, como testemunha o artigo: De l'air! De l'espace! Des jeux! (HÉBERT, 1912). Ele propaga uma medicina higiênica, esportiva, denunciando a atitude de práticos que, no século XIX, "duvidavam do exercício por medo de esforço, da ação vivificante do ar livre e até mesmo o calor do sol” (HÉBERT, 1912, p. 91). 
Para obter resistência, o organismo deve ser confrontado com o frio, o calor, o sol e as intempéries do trabalho ao ar livre por meio "dos banhos de ar e de sol, grandes banhos de rio ou de mar, o uso de água fria para as abluçóes" (HÉBERT, 1912, p. 5). O Método difunde os princípios de uma vida em harmonia com as leis da natureza, dando livre curso à sua "necessidade natural" para a atividade supóe assimilar, portanto, o modelo racial ao "não civilizado". A educação do corpo do ser civilizado deve encontrar nos exercícios a atividade que "representaria um dia inteiro de vida ao ar livre, sendo associada à um estado livre” (HÉBERT, 1912, p. 9).

$\mathrm{O}$ respeito às leis da natureza implica esse trabalho ao ar livre e os banhos de sol. O livre jogo do corpo nu, das articulaçôes e dos músculos é a condição do jogo ao ar livre e de seu Método Natural. Assim, esses jogos corporais livres de restriçóes artificiais devem ser realizados por intermédio de movimentos naturais: andar; correr; saltar; escalar; elevar; jogar; defender-se; sempre que possível, nadar; tomar um banho de ar com duração variável, seguindo as condiçóes atmosféricas; e cuidar da pele após o trabalho. As qualidades naturais do corpo são ativadas por exercícios de "resistência, velocidade, força muscular, coordenaçáo geral e específica, qualidades viris, resistência geral do organismo, frugalidade" (HÉBERT, 1912, p. 30).

O exemplo de jovens marinheiros, cuja aptidão física deve ser assegurada pela resistência às corridas de fundo e à natação, no mar ou em piscinas, revela bem "seu treinamento no frio, no calor ou sob o sol escaldante” (HÉBERT, 1912, p. 47). A saúde adquirida por esses exercícios prova que "os banhos de ar melhoram o estado de seu organismo de uma maneira potente" (HÉBERT, 1912, p. 52). Ele especifica que, quase nos dez meses do ano, "o banho de ar pode ser praticado com o torso nu, ao ar livre, até 5 graus abaixo de zero, no tempo calmo de janeiro de 1909” (HÉBERT, 1912, p. 52).

Ainda acrescenta: "ar e luz são os primeiros alimentos necessários para a pele. Sob a influência do ar e da luz, a pele perde sua aspereza e sua aparência lívida; ela adquire uma cor bronzeada característica e torna-se extremamente suave ao toque" (HÉBERT, 1912, p. 63). Assim, adotar as condiçôes mesmas da vida natural: o trabalho ao ar livre, bem como os banhos de ar e de sol provam o quanto "o ser humano, por sua natureza mesma, está organizado para viver ao ar livre com seu envelope natural que é a pele" (HÉBERT, 1912, p. 84). 
Para Hébert (1912), a verdadeira força reside, antes de tudo, na energia que se utiliza, na vontade que dirige ou no sentimento que guia. Trata-se de uma síntese física, viril e moral. "Na ordem puramente física a força consiste, de um lado, possuir um certo número de qualidades: resistência orgânica, muscular, velocidade, coordenação; de outro lado, o controle dos fez grupos de exercícios fundamentais. $\mathrm{Na}$ ordem viril, a força consiste em possuir energia suficiente, vontade, coragem, sangue frio, firmeza. $\mathrm{Na}$ ordem moral, a força pode também consistir em fazer tanto o mal quanto o bem". A máxima desse método é "ser forte para ser útil". Ela tem dois aspectos fundamentais: a confrontação permanente ao ar livre e a variedade dos meios naturais e humanos aos quais os praticantes são confrontados.

Esse método repertoria os seus exercícios em dez grupos fundamentais: marchar, correr, saltar, movimento quadrupede, escalar, equilibrar-se, carregar, levantar e arremessar pesos, defender-se, nadar. Ele é praticado em dois lugares: percursos naturais e ginásios. O Método Natural se funda sobre avaliaçóes precisas, fichas individualizadas para avaliar os progressos. A respiração no exercício e o esporte tornam-se desde então uma norma de saúde (RICHARD,1927).

No Guide Pratique d'Éducation physique, Hébert (1909) fundamenta seu método de treinamento com base na resistência ao frio e às intempéries que se faz "naturalmente ao se trabalhar com o torso nu, ao ar livre e em todas as estaçóes" (HÉBERT, 1909, p. 8). Na obra Le code de la force, de 1910, ele estima que a nudez pudica com fins de resistência é a condição necessária para os exercícios ao ar livre e os banhos de sol, opondo-se, assim, àqueles que duvidam do exercício por medo do contato mais direto com a natureza e suas condições climáticas (HÉBERT, 1910). Em 1912, o banho de sol, como o banho de ar, é considerado, no mito do selvagem, um meio para respeitar as leis da natureza, posto que "o corpo nu ou livre de tudo que possa impedir o livre jogo das articulaçóes e dos músculos; bem como o funcionamento regular da pele" (HÉBERT, 1912, p. 81).

Tissié (1914) afirma que o Marquês Melchior de Polignac (1880-1950), em seu parque Pommery, em Reims, criou um terreno reservado para os atletas se exercitarem seminus. Em 1913, Georges Hébert, diretor do Parque Pommery, será o responsável pela gestão das atividades ao ar livre, dos banhos de sol e de luz, da hidroterapia, das massagens, dos exercícios físicos, dos banhos de piscina e, durante o in- 
verno, banhos de neve. Não havia mistura dos sexos, pois as mulheres frequentavam um estádio particular.

Tissié (1914) relata, ainda, que uma aplicação do Método Natural foi realizada nas 33 escolas primárias e liceus da cidade de Reims, acolhido pela simplicidade de seus exercícios baseados nas atividades naturais como andar, saltar, elevar-se, entre outros movimentos. O Parque Pommery já oferecia todas as instalaçóes necessárias para o bom funcionamento desse colégio, o que suscita algumas polêmicas. Alguns intelectuais chocaram-se pelo acoplamento da palavra colégio à palavra atletas, um colégio de atletas; outros qualificavam esse colégio como uma "boutique de músculos", "boîte à bachot" [fábrica de bacharéis] para candidatos aos jogos olímpicos. Contudo, o novo método seduzia muito os jovens que se desagradam dos sistemas tediosos de educaçáo física praticados nas escolas. Em 6 meses, uma pista oval, um ginásio coberto de 40 × 20 metros e uma piscina ao ar livre foram construídos, acompanhados de salas de boxe e esgrima.

Em 1913, o Campo de Treinamento La Palestra, com dependências para os ginásios feminino e infantil, foi fundado nos arredores da praia de Deauville, Mar dos Calvados. O regime de uma vida rústica, em tendas, consiste em "uma escola tanto de cultura mental quanto de cultura corporal” (HÉBERT, 1912; 1925a; 1925b; 1936). Uma educação física feminina se delineava, considerando-se que o caráter nervoso das moças estaria na falta de atividade física e em uma vida sedentária e artificial. Assim, prescreve-se que, por meio do contato constante com o ar livre, banhos de ar e de sol, exercícios e uma alimentação frugal, seria possível libertar o organismo de todas as suas impurezas, aumentando suas defesas naturais contra as doenças (HÉBERT, 1912; 1925a; 1925b; 1936).

Fortalecer a saúde, desenvolver os músculos, treinar o corpo, tornar o organismo resistente, simplificar a vida, desenvolver o sentido prático são os objetivos buscados no campo e na educação física feminina. Assim, as moças precisam educar o corpo e o espírito pela busca de uma harmonia e de um equilíbrio, evitando o relaxamento e a preguiça, treinando-se em boa saúde ao ar livre. $\mathrm{O}$ apoio com as máos, a luta corporal, a corrida em velocidade, a camuflagem, o rastejar, o basquetebol (o jogo americano da moda), o tiro ao arco, os exercícios de canoagem, a natação e a dança se organizam em torno de diferentes espaços: o ginásio de dança, o de jogos e o grande estádio de treinamento (HÉBERT, 1912). 
Ao estudar arquivos médicos, datados de janeiro de 1914, Hébert (1941), afirma que o Dr. Marcel Didier, médico do Colégio de Reims, apresenta com precisão a ficha de treinamento na qual se encontra "a autorização ou a interdição do treinamento livre, do banho de ar e de sol, da hidroterapia e do banho frio" (HÉBERT, 1941, p. 87). Como precisa Villaret (2005, p. 92), os banhos de sol são realizados "deitados sobre encostas verdejantes que circundam o estádio e pontuam as jornadas dos alunos".

Desde 1919, o Instituto Naturista do Dr. Didier, situado no número 24 Chemin Pouyane na cidade de Argel, dedica-se à higiene e à medicina por meio dos agentes naturais: ar, sol, exercícios físicos, água, regimes alimentares para o tratamento de distúrbios crônicos, digestão, circulação e nutrição (DIDIER, 1930). Nesse contexto climático, a cidade de Argel, capital da Argélia, no norte da África, foi escolhida para ser a capital francesa do "Músculo e do Naturismo" durante a estação do inverno. Nesse contexto, aeração e insolação, hidroterapia e regime alimentar tornam-se meios terapêuticos. Nesse texto extremamente colonialista, o retorno à natureza pode, sozinho, refazer uma raça forte (DIDIER, 1930). O Dr. Didier deseja aproveitar-se dessa máxima para estudar a raça árabe e os costumes algerianos. Considerando-se 2 ou 3 sessóes por semana de "cultura física médica" sob a sua direção ou de seu assistente, cursos gerais para sujeitos bem-comportados (7 a 12 alunos), distinguem-se dos "cursos restritos aos sujeitos doentios ou cansados ( 2 a 6 alunos), e liçóes particulares para os doentes. No instituto, praticam-se também a massagem médica local ou geral e a massagem facial. O banho ao ar livre é completado pelo banho de sol em uma estufa, ao abrigo do vento. O colonialismo apropriase do termo colônia naturista, confundindo o comunitarismo naturista e nudista com a conquista de novos territórios nos quais a nudez pública e a vida ao ar livre não são contidos por princípios religiosos.

O Método Natural irá, portanto, unir naturismo e educação física como uma educação corporal que visa a compensar as consequências prejudiciais de uma sociedade industrializada e doentia, buscando reinscrever os indivíduos na ordem natural. Educar-se ao ar livre, envolto por paisagens naturais e em contato com os elementos da natureza, apresenta-se como uma alternativa diante da emergência do maquinismo da vida moderna e seu perigo para a integridade física e psíquica do indivíduo, sendo, ainda, conforme aponta Suquet (2012), sintoma de degeneração próprio à civilização industrial e, em particular, aos ritmos do trabalho. 


\section{A RÍTMICA DE ÉMILE JAQUES-DALCROZE}

Jaques-Dalcroze foi um artista, músico, compositor e pedagogo austríaco que viveu na Suíça, onde criou a Rítmica, método que busca articular a individualidade, o temperamento, o estado fisiológico e psicológico habitual ou momentâneo daquele que exprime algo. Irá apresentar uma crítica à imitação na arte, em particular na dança. Para ele, é necessário harmonizar os meios de expressão corporal a partir da influência das emoçóes mais profundas e das sensaçóes mais delicadas. Assim, ele questiona pintores que não sabem olhar, músicos que só o são por conta do instrumento, dançarinos que apenas usam o corpo, mas que não pensam ou não expressam sentimentos (JAQUES-DALCROZE, 1916). Jaques-Dalcroze é um pioneiro que participa com outros artistas visionários de uma revolução na maneira de ver a música, a pedagogia, a cena, a expressáo corporal, a vida por meio da unidade de espaço, tempo e energia. Ele colocou o corpo no centro de uma educação nova, relacionando-o à música e à emoção.

O encontro com Adolphe Appia, em 1906, será decisivo para o desenvolvimento - com o apoio do mecenas Wolf Dorhn - de seu projeto pedagógico, com a criação do futuro Instituto Dalcroze. Neste, previu-se a construçáo de espaços que podiam ser transformados e que, junto com uma iluminação adequada, apresentavam múltiplas possibilidades para a formação dos alunos, para a criação artística e para a encenação de espetáculos nos quais os diversos módulos e escadarias podiam ser investidos tanto pelos artistas quanto pelos espectadores. De acordo com Kuschning e Pellois (2015), o emprego anual do tempo de um rythmicien (praticante de rítmica) era distribuído em 24 horas semanais, sendo composto, aproximadamente, por: 3 sessóes de 30 minutos de ginástica sueca; 2 horas de ginástica rítmica; 6 horas divididas em solfejo, teoria e canto; 6 horas para aulas de dança, 6 horas de teatro e 6 horas de plástica; 1 hora para aula de anatomia; e 2 horas para curso de expressáo gestual. Havia, ainda, a previsão de 2 horas para a livre escolha do aluno.

Segundo Madureira e Banks-Leite (2010), com o advento da Primeira Guerra Mundial, as atividades do Instituto de Hellerau foram suspensas. De volta para casa, graças à campanha para angariar fundos, dirigida por amigos e compatriotas influentes, entre os quais, Jacques Chenevière, Auguste de Morsier e Édouard Claparède, foi possível inaugurar, no dia 14 
de outubro de 1915, o Instituto Dalcroze, em Genebra. "Cabe assinalar que Édouard Claparède já era, no princípio do século XX, um eminente professor e pesquisador reconhecido por seus trabalhos em psicologia e pela fundação, em 1912, do Instituto Jean-Jacques Rousseau, destinado à formação de educadores com ênfase na educaçáo infantil. Os dois institutos colaboraram estreitamente para implementar a educação de crianças pequenas, uma vez que a escola 'Maison des Petits' funcionava como anexo do Instituto JeanJacques Rousseau. Além disso, Dalcroze voltou-se, ele próprio, a partir da década de 1920, ao ensino de atividades de rítmica para crianças com necessidades especiais, ou seja, crianças surdas, cegas e outras que apresentavam atrasos intelectuais" (MADUREIRA; BANKS-LEITE, 2010, p. 216).

O método La Gymnastique rythmique - publicado em dois volumes: La Rythmique I (1916) e La Rythmique II (1917) — e a obra Le Rythme, la musique et l'éducation (1965) apresentam a concepção do método e dos exercícios para o desenvolvimento do ritmo, da métrica musical, do sentido da harmonia e da plasticidade dos movimentos e da educação. "Os alunos marcham conforme valores: um passo para o negro, um passo com flexão para o branco, um passo seguido de vários movimentos, cruzamento de pernas para marcar o tempo em círculo" (KUSCHNING; PELLOIS, 2015, p. 31).

Para Dalcroze, a ginástica rítmica é um método de educação geral. "Ela se dirige ao olho e à orelha, desperta e desenvolve o sentido muscular. A criança apodera-se de seus movimentos, regularizando sua dinâmica, sua duração, e sua extensão [no espaço]. É assim, que sua mentalidade, sua vontade, sua imaginação e seu julgamento tomam forma” (JAQUES-DALCROZE, 1916, p. 281). O despertar do sentido muscular e a consciência do ritmo integram o seu método, com atenção para os indicadores corporais, tais como os batimentos cardíacos, a respiraçáo e a marcha, tidos como matrizes rítmicas. O método é composto por exercícios gerais de respiração, equilíbrio, força e flexibilidade dos músculos; e por exercícios de ritmo, tais como a marcha e as práticas de coordenação de braços e pernas. Os alunos são organizados em fileiras, formando linhas, um ao lado do outro. Devem vestir-se com trajes leves que possam facilitar a amplitude de movimentos.

Em Souvenirs, notes et critiques, Jaques-Dalcroze (2011) faz um elogio a Fred Astaire e à sua nova dança plena de imaginação, de beleza e de emoção. 
Em uma apresentação, faz-se necessário que o dançarino se deixe penetrar pela vida múltipla que anima o sujeito. Ele deve situar-se em todos os cantos e recantos de seu organismo, olhar em torno de si, de perto e de longe, interrogar o horizonte, buscar penetrar além, evadir-se da matéria, evocar todas as imagens, comparaçóes, lembranças, humores e todos os perfumes dos jardins. Embalar-se ao vento, absorver os jogos da luz, refrescar-se em suas flamas e iluminar-se com seus raios. (JAQUES-DALCROZE, 2011, p. 104)

Além dessa relação com a natureza, Dalcroze aponta, em seu método, para a necessidade de se criar relaçóes com o outro e com o espaço. Explorar as sensaçóes e os sentimentos é o elemento principal de sua educação dos sentidos que irá enriquecer a experiência rítmica e artística. Ao final do século XIX, por meio métodos de exercício corporal, novas expressóes de dança emergem com Laban, Isadora, Delsarte e outros pioneiros. A rítmica de Dalcroze, inicialmente destinada à educação musical, revela-se eficiente para a dança, em particular quando associada aos trabalhos de Mary Wigman e Rudolf Laban, como nos mostra Berchtold (2000), em sua ênfase rítmica para liberação do corpo e do movimento. Esse mesmo aspecto rítmico irá afastá-los, dado que ambos concebiam a possibilidade de uma dança independente da musicalidade, o que para Dalcroze era impossível.

Inicialmente destinada à educação de músicos, o método criado por Dalcroze, em sua ênfase corporal, irá reverberar nos campos da dança, notadamente nos trabalhos de Isadora Duncan e de Rudolf Von Laban, revelando a organicidade do corpo e de seus ritmos transformados em gestos que se reatualizam na cena contemporânea e na cena educativa.

\section{CONSIDERAÇÕES FINAIS}

A gênese dos projetos naturistas de educação funda-se em uma renovação das representações da natureza, seus usos e a relação dos indivíduos com seu corpo no contexto das sociedades modernas. No fim do século XIX e início do século XX, o naturismo ocupa um espaço relevante no campo da educação física e dos esportes, com a difusão das curas naturais e o crescimento de uma nova sensibilidade concernente à vida 
moderna, que exige um retorno à natureza e o contato com os elementos naturais. Nesse contexto, destaca-se também a busca do movimento natural, original, criativo encampado por Georges Hébert, mas também por outros pioneiros, como é o caso de Émile Jaques-Dalcroze.

A leitura das obras de Georges Hébert e de Jaques-Dalcroze evidencia o imbricamento das relaçóes entre corpo, natureza e cultura. $\mathrm{O}$ contato com a natureza como meio de educar o corpo e seus sentidos cinestésicos alia-se a um programa de reforma moral, social e estética. Trata-se de um projeto social mais amplo, que busca fazer frente às ameaças da vida moderna, notadamente diante dos processos de industrialização emergentes no contexto histórico estudado. Passa-se a buscar uma maior consciência do homem em seu ambiente natural e um retorno às fontes naturais, posto que o homem se encontra "fora da natureza”, sendo a sociedade representada como um lugar de corrupçáo do indivíduo. Nesse sentido, o naturismo está ligado não apenas às condiçôes higiênicas, ao exercício ao ar livre, mas a uma busca de religar o homem com as energias e os fluxos vitais, conforme a analogia entre o microcosmo e o macrocosmo, harmonizando os movimentos humanos com os ritmos da natureza, seja no Método Natural de Georges Hébert, seja na Rítmica proposta por Jaques-Dalcroze ou em outras pedagógicas corporais disseminadas no interior da educação física, delineando-se uma nova sensibilidade que considera a inteligibilidade do corpo, de seus gestos e sentidos cinestésicos.

Compreendemos que essas referências históricas e filosóficas atravessam a educação do corpo em um processo de ecologia corporal e das ideias. Cabe esclarecer que a ecologia corporal é uma prática de si que se ocupa do cuidado dos outros por meio de escolhas de vida (ANDRIEU, 2011; 2017). Não se trata de um retorno a um estado de natureza ideal, mas da observação de nosso estilo de vida, de nossos modos de produção e de consumo; bem como de nossos modos de relaçáo afetiva e de elaboração cognitiva, que germinam nas práticas educativas contemporâneas em busca de um modo de vida complexo, ecológico e ecologizante.

\section{REFERÊNCIAS}

ANDRIEU, B. A osmose solar: colorir a pele ou mergulhar no calor? In: SOARES, C. (Org.). Uma educação pela natureza: a vida ao ar livre, o corpo e a ordem urbana. Campinas: Autores Associados, 2016. 
ANDRIEU, B. En plein soleil: vers l'énergie. Biarritz: Atlantica, 2011. . L'écologie corporelle. Paris: L’Harmattan, 2017. 2 v.

BAUBEROT, A. Histoire du naturisme: le mythe du retour à la nature. Rennes: Presse Universitaire de Rennes, 2004.

BERCHTOLD, A. Emile Jacques-Dalcroze et son temps. Lausanne: L'age d'Homme, 2000.

DIDIER, M. La culture physique et la naturisme sous le soleil d'Alger: les tendances nouvelles de l'hygiène. Paris: Broché, 1930.

HÉBERT, G. Guide pratique d'Education physique. Paris: Vuibert, 1909.

. Le code de la force. Paris: Vuibert, 1910.

. L'éducation physique ou l'entraînement complet par la méthode naturelle.

Paris: Vuibert, 1912.

. L'éducation physique ou l'entraînement complet par la méthode naturelle. Historique-documentaire. Paris: Vuibert, 1941.

. L'Éducation physique, virile et morale par la Méthode Naturelle. Paris: Vuibert, 1936. v. 1. . Le Sport contre l'Éducation physique. Paris: Vuibert, 1925a.

- Une institution originale: les palestres d'hiver et d'été du collège gymnique La Palestra. Paris: Vuibert, 1925 b.

JAQUES-DALCROZE, É. La Gymnastique Rythmique I. Lausanne: Jobin et Cie, 1916.

. Le rythme, la musique et l'éducation. Lausanne: Foetisch Frères, 1965.

. Souvenirs, notes et critiques. In: MACEL, C.; LAVIGNE, E. (Orgs.). Danser sa vie: écrits sur la danse. Paris: Centre Pompidou, 2011. p. 101-107.

KUSCHNING, C.; PELLOIS, A. (Orgs.). Le rythme. Une révolution! Émile Jacques-Dalcroze à Hellerau. Genève: Slatkine, 2015.

MADUREIRA, R.; BANKS-LEITE, L. Jacques-Dalcroze: música e educação. Pro-Posiçôes, Campinas, v. 21, n. 1, p. 215-218, jan./abr. 2010.

MONTAIGNE, M. Ensaios. São Paulo: Abril Cultural, 1972. (Coleção Os Pensadores).

NÓBREGA, T.P. Corporeidades... inspiraçōes merleaupontianas. Natal: Editora IFRN, 2016. 
PHILIPPE-MEDEN, P. Corporéité hébertiste et philosophie mystique. Horizons/théâtre, n. 4, p. 135-145, 2014.

. Du Sport à la scène: le naturisme de Georges Hébert (1875-1957). Bordeaux: PUB, 2017.

REVEL, J. Foucault avec Merleau-Ponty: ontologie politique, présentisme et histoire. Paris: Vrin, 2015.

RICHARD, G.A. La respiration dans l'exercice et le sport: l'éducation respiratoire. Paris: Legrand, 1927.

ROUSSEAU, J-J. Emílio ou da educação. São Paulo: Martins Fontes, 1995.

SOARES, C. (Org.). Uma educação pela natureza: a vida ao ar livre, o corpo e a ordem urbana. Campinas: Autores Associados, 2016.

SOARES, C.L. Imagens da Educação Física no corpo: estudos a partir da ginástica francesa no século XIX. Campinas: Autores Associados, 1998.

SUQUET, A. L'éveil des modernités: une histoire culturelle de la danse (18701945). Pantis: CND, 2012.

VILLARET, S. Naturisme et éducation corporelle: des projets réformistes aux prises en compte politiques et éducatives. Paris: L'Harmattan, 2005.

TISSIE, P. L'homme nu: la Méthode Naturelle et le Collège d'Athlètes de Reims. Critique physiologique, pédagogique et médicale. Revue des Jeux Scolaires et D'hygiene Sociale, p. 17-59, 1914.

WAILLE, F. La méthode somatique expressive de François Delsarte. Lavérune: L'Entretemps, 2016.

Recebido em 24 de abril de 2017.

Aprovado em 12 de setembro de 2017. 